\title{
The Synthesis and Characterization of Novel Bis-cationic Asphalt Emulsifier
}

\author{
Xiao-Meng Yu, Lai-Shun Shia, Cun-Fei Ma, Lu Hou, Jing-Wen Kong and Ya-Li Sun \\ School of Chemistry and Chemical Engineering, Shandong University, Jinan 250061, P. R. China
}

\begin{abstract}
Three novel bis-cationic asphalt emulsifiers were synthesized by two steps reaction of N-tallow-1,3diaminopropane, methyl acrylate, sodium hydroxide and chloroacetic acid. The structure of the product was confirmed by FTIR, ${ }^{1} \mathrm{H}$ NMR and elemental analysis. The emulsifier exhibits satisfactory emulsification. The prepared bituminous emulsion showed higher storage stability. The emulsifier belongs to medium-set and slow-set asphalt emulsifier. It can be designed to perform in a wide variety of applications including tack coat, fog seal, chip seal and slurry seal in asphalt pavement construction.
\end{abstract}

\section{Introduction}

Asphalt has many excellent properties such as good adhesion properties, aging resistance and water resistance. It is widely used in road repair, waterproofing materials, sealing materials, etc [1]. Emulsified asphalt performance depends on the nature of the asphalt emulsifier. According to the different charge of asphalt emulsifier, it is divided into cationic, anionic, nonionic, amphoteric [2]. In recent years, it is widely used and studied due to the good performance, high adhesion of cationic asphalt emulsifier [3]. Negm [4] synthesized a series of cationic surfactants with benzaldehyde, $\mathrm{p}$-aminopyridine, xylene, 1,2-dibromoethane, 1,6-dibromohexane and 1,12dibromododecane by two-step reaction. Li [5] synthesized an asymmetric Gemini cationic surfactants, characterized its structure and discussed the affect factors of stability.

Depending on the breaking speed of asphalt emulsifier, it is divided into slow, rapid, and medium set type. Slow set asphalt emulsifier [6] is a key material for slurry seal. Slurry seal [7] is solid surface sealing layer which emulsified asphalt, water, aggregates and slag mix by a certain percentage forming a paste and flow of synthetic slurry mixture and then spread evenly on the road. Rapid set emulsifier [8] is mainly used for chip seal layer and spray patching potholes. Fracturing chippings overlay often uses the medium set type emulsifier [9].

In previous papers, we have synthesized different kinds of asphalt emulsifiers [10-14]. Three novel biscationic asphalt emulsifiers were synthesized by two steps reaction in this paper. The structure of the emulsifier was confirmed by FTIR, ${ }^{1} \mathrm{H}$ NMR and elemental analysis.

\section{Experimental}

\subsection{Materials and characterization}

N-tallow-1,3-diaminopropane was technical grade and obtained from Zibo HuaRun Chemical Co., Ltd, Zibo, China. All the other reagents were of analytical reagent grade and used without further purification. The asphalt used was AH-90, which was provided by Shengli Refinery of Qilu Petrochemical Company, Zibo, China. The mineral aggregate was the mixture of different size of marble stone. The FTIR spectra were recorded from 400 to $4000 \mathrm{~cm}^{-1}$ wavenumber range with averaging 32 scans at a resolution of $4 \mathrm{~cm}^{-1}$ on a Bruker Tensor-27 FTIR spectrophotometer. The ${ }^{1} \mathrm{H}$ NMR spectra were recorded on a Bruker Avance 300M NMR spectrometer (Bruker, Germany), using $\mathrm{D}_{2} \mathrm{O}$ as solvent and TMS as internal reference. Chemical shifts $(\delta)$ were given in ppm. Elemental analyses were performed by the Elementar vario EL type III element analyzer (Elementar, German).

\subsection{Synthesis of asphalt emulsifier}

Scheme 1 shows the synthesis route of the bis-cationic asphalt emulsifier (A). $\mathrm{C}_{18} \mathrm{H}_{37} \mathrm{NH}\left(\mathrm{CH}_{2}\right)_{3} \mathrm{NH}_{2}+\mathrm{CH}_{2}=\mathrm{CHCOOCH}_{3} \longrightarrow$

$\mathrm{C}_{18} \mathrm{H}_{37} \mathrm{NH}\left(\mathrm{CH}_{2}\right)_{3} \mathrm{NH}\left(\mathrm{CH}_{2}\right)_{2} \mathrm{COOCH}_{3}$ (Intermediate)

$\mathrm{C}_{18} \mathrm{H}_{37} \mathrm{NH}\left(\mathrm{CH}_{2}\right)_{3} \mathrm{NH}\left(\mathrm{CH}_{2}\right)_{2} \mathrm{COOCH}_{3}+2 \mathrm{ClCH}_{2} \mathrm{COONa}+\mathrm{H}_{2} \mathrm{O} \longrightarrow$ $\mathrm{CH}_{2} \mathrm{COONa}$

$\mathrm{C}_{18} \mathrm{H}_{37} \mathrm{NH}^{+}\left(\mathrm{CH}_{2}\right)_{3} \mathrm{NH}^{+}\left(\mathrm{CH}_{2}\right)_{2} \mathrm{COOH} \cdot 2 \mathrm{Cl}-\mathrm{CH}_{3} \mathrm{OH}$ $\mathrm{CH}_{2} \mathrm{COONa}$

Scheme 1. Synthetic route of asphalt emulsifier (A).

\footnotetext{
${ }^{a}$ Corresponding author: LSHUNSH@sdu.edu.cn
} 
N-tallow-1,3-diaminopropane (326.0 g, $1.00 \mathrm{~mol}$ ) and $400 \mathrm{~g}$ isopropanol were added in a three-necked flask, and heated to $70{ }^{\circ} \mathrm{C}$ in a water bath. Methyl acrylate $(90.3$ $\mathrm{g}, 1.05 \mathrm{~mol})$ was added dropwise and reacted for $4 \mathrm{~h}$. The reaction solution was processed by vacuum distillation to remove the solvent, then recrystallized with anhydrous ethanol for three times to obtained the intermediate.

Sodium chloroacetate aqueous solution was synthesized by the reaction of $196.6 \mathrm{~g}(2.08 \mathrm{~mol})$ chloroacetic acid, $83.2 \mathrm{~g}(2.08 \mathrm{~mol}) \mathrm{NaOH}$ and $560.0 \mathrm{~g}$ distilled water. Then the sodium chloroacetate aqueous solution was added dropwise to the reaction solution synthesized above and stirred for $5 \mathrm{~h}$ at $65^{\circ} \mathrm{C}$ in water bath. Finally, the reaction solution was processed by vacuum distillation to remove the solvent, then recrystallized with anhydrous ethanol for three times to obtained the product.

Scheme 2 shows the synthesis route of the biscationic asphalt emulsifier (B).

$\mathrm{C}_{18} \mathrm{H}_{37} \mathrm{NH}\left(\mathrm{CH}_{2}\right)_{3} \mathrm{NH}_{2}+2 \mathrm{CH}_{2}=\mathrm{CHCOOCH}_{3} \longrightarrow$

$\mathrm{C}_{18} \mathrm{H}_{37} \mathrm{NH}\left(\mathrm{CH}_{2}\right)_{3} \mathrm{~N}\left(\mathrm{CH}_{2} \mathrm{CH}_{2} \mathrm{COOCH}_{3}\right)_{2}$

$\mathrm{C}_{18} \mathrm{H}_{37} \mathrm{NH}\left(\mathrm{CH}_{2}\right)_{3} \mathrm{~N}\left(\mathrm{CH}_{2} \mathrm{CH}_{2} \mathrm{COOCH}_{3}\right)_{2}+2 \mathrm{ClCH}_{2} \mathrm{COONa}+2 \mathrm{H}_{2} \mathrm{O} \longrightarrow$ $\mathrm{CH}_{2} \mathrm{COONa}$

$\mathrm{C}_{18} \mathrm{H}_{3} \mathrm{NH}^{+}\left(\mathrm{CH}_{2}\right)_{3} \mathrm{~N}^{+}\left(\mathrm{CH}_{2} \mathrm{CH}_{2} \mathrm{COOH}\right)_{2} \cdot 2 \mathrm{Cl}^{-}+2 \mathrm{CH}_{3} \mathrm{OH}$ $\stackrel{\mathrm{C}}{\mathrm{C}} \mathrm{H}_{2} \mathrm{COONa}$

Scheme 2. Synthetic route of asphalt emulsifier (B).

N-tallow-1,3-diaminopropane (326.0 g, $1.00 \mathrm{~mol}$ ) and $400 \mathrm{~g}$ isopropanol were added in a three-necked flask, and heated to $70{ }^{\circ} \mathrm{C}$ in a water bath. Methyl acrylate (175.5 g, $2.04 \mathrm{~mol}$ ) was added dropwise and reacted for 4h. The reaction solution was processed by vacuum distillation to remove the solvent, then recrystallized with anhydrous ethanol for three times to obtained the intermediate.

Sodium chloroacetate aqueous solution was synthesized by the reaction of $196.6 \mathrm{~g}$ (2.08 mol) chloroacetic acid, $83.2 \mathrm{~g}(2.08 \mathrm{~mol}) \mathrm{NaOH}$ and $560.0 \mathrm{~g}$ distilled water. Then the sodium chloroacetate aqueous solution was added dropwise to the reaction solution synthesized above and stirred for $5 \mathrm{~h}$ at $65^{\circ} \mathrm{C}$ in water bath. Finally, the reaction solution was processed by vacuum distillation to remove the solvent, then recrystallized with anhydrous ethanol for three times to obtained the product.

Scheme 3 shows the synthesis route of the biscationic asphalt emulsifier $(\mathrm{C})$.

$\mathrm{C}_{18} \mathrm{H}_{37} \mathrm{NH}\left(\mathrm{CH}_{2}\right)_{3} \mathrm{NH}_{2}+3 \mathrm{CH}_{2}=\mathrm{CHCOOCH}_{3} \longrightarrow$

$\mathrm{C}_{18} \mathrm{H}_{37} \mathrm{~N}\left(\mathrm{CH}_{2}\right)_{3} \mathrm{~N}\left(\mathrm{CH}_{2} \mathrm{CH}_{2} \mathrm{COOCH}_{3}\right)_{2}$ $\mathrm{CH}_{2} \mathrm{CH}_{2} \mathrm{COOCH}_{3}$

$\mathrm{C}_{18} \mathrm{H}_{37} \mathrm{~N}\left(\mathrm{CH}_{2}\right)_{3} \mathrm{~N}\left(\mathrm{CH}_{2} \mathrm{CH}_{2} \mathrm{COOCH}_{3}\right)_{2}+2 \mathrm{ClCH}_{2} \mathrm{COONa}+3 \mathrm{H}_{2} \mathrm{O} \longrightarrow$

$\mathrm{CH}_{2} \mathrm{CH}_{2} \mathrm{COOCH}_{3}$

$\mathrm{CH}_{2} \mathrm{CH}_{2} \mathrm{COOH}$

$\mathrm{C}_{18} \mathrm{H}_{37} \mathrm{~N}^{+} \mathrm{CH}_{2} \mathrm{CH}_{2} \mathrm{CH}_{2} \mathrm{~N}^{+}\left(\mathrm{CH}_{2} \mathrm{CH}_{2} \mathrm{COOH}\right)_{2} \cdot 2 \mathrm{Cl}^{-}+3 \mathrm{CH}_{3} \mathrm{OH}$

$\mathrm{CH}_{2} \mathrm{COONa} \quad \mathrm{CH}_{2} \mathrm{COONa}$

Scheme 3. Synthetic route of asphalt emulsifier (C).

$\mathrm{N}$-tallow-1,3-diaminopropane (326.0 g, $1.00 \mathrm{~mol})$ and $400 \mathrm{~g}$ isopropanol were added in a three-necked flask, and heated to $70{ }^{\circ} \mathrm{C}$ in a water bath. Methyl acrylate (261.6 g, $3.04 \mathrm{~mol}$ ) was added dropwise and reacted for $4 \mathrm{~h}$. The reaction solution was processed by vacuum distillation to remove the solvent, then recrystallized with anhydrous ethanol for three times to obtained the intermediate.

Sodium chloroacetate aqueous solution was synthesized by the reaction of $196.6 \mathrm{~g}(2.08 \mathrm{~mol})$ chloroacetic acid, $83.2 \mathrm{~g}(2.08 \mathrm{~mol}) \mathrm{NaOH}$ and $560.0 \mathrm{~g}$ distilled water. Then the sodium chloroacetate aqueous solution was added dropwise to the reaction solution synthesized above and stirred for $5 \mathrm{~h}$ at $65^{\circ} \mathrm{C}$ in water bath. Finally, the reaction solution was processed by vacuum distillation to remove the solvent, then recrystallized with anhydrous ethanol for three times to obtained the product.

\subsection{Performance test of bituminous emulsion}

\subsubsection{Preparation of bituminous emulsion}

$12.5 \mathrm{~g}$ emulsifier was dissolved in $200 \mathrm{ml}$ water, then the solution was heated to $60{ }^{\circ} \mathrm{C}$. The $\mathrm{pH}$ value of the aqueous solution was adjusted to 2.0 by adding hydrochloric acid. $300 \mathrm{~g} \mathrm{AH}-90$ asphalt was heated to $120{ }^{\circ} \mathrm{C}$. The bituminous emulsion was prepared by mixing the aqueous solution containing emulsifier and asphalt in a colloid mill for $1 \mathrm{~min}$.

\subsubsection{Demulsification speed test of bituminous emulsion}

Demulsification speed of bituminous emulsion was determined according to T0658-1993 standard. B type mineral aggregate $(200 \mathrm{~g})$ and water $(30 \mathrm{~g})$ were placed in a $500-\mathrm{mL}$ bowl. Bituminous emulsion $(50 \mathrm{~g})$ was then added, and the mixture was stirred for $1 \mathrm{~min}$ at 60 revolutions per minute. The mixing time and the appearance were recorded by observing the uniform of the aggregate mixing performance.

\section{Results and discussion}

\subsection{Structure characterization of intermediate}

Figure 1 gives the FTIR spectrum of the intermediate in Scheme 1. The absorption at $3275 \mathrm{~cm}^{-1}$ (peak 1) is assigned to the N-H stretching. The absorption at 2917 $\mathrm{cm}^{-1}$ (peak 2) is assigned to the methyl asymmetrical stretching. The absorption at $2854 \mathrm{~cm}^{-1}$ (peak 3) is assigned to the methylene symmetrical stretching. The absorption at $1735 \mathrm{~cm}^{-1}$ (peak 4) is assigned to $\mathrm{C}=\mathrm{O}$ stretching of ester. The absorption at $1569 \mathrm{~cm}^{-1}$ (peak 5) is assigned to $\mathrm{N}-\mathrm{H}$ bending vibration. The absorptions at $1470 \mathrm{~cm}^{-1}$ (peak 6) and $1376 \mathrm{~cm}^{-1}$ (peak 7) are assigned to the methyl asymmetrical and symmetrical bending vibration, respectively. The absorption at $1207 \mathrm{~cm}^{-1}$ (peak 8 ) is assigned to $\mathrm{C}-\mathrm{N}$ stretching. The absorption at 1125 $\mathrm{cm}^{-1}$ (peak 9) is assigned to $\mathrm{C}-\mathrm{O}-\mathrm{C}$ stretching. The absorption at $724 \mathrm{~cm}^{-1}$ (peak 10) is assigned to methylene in-plane swing vibration. Therefore, the FTIR spectrum agrees with the chemical structure of the intermediate to be synthesized. 


\subsection{Structure characterization of asphalt emulsifier (A)}

Figure 2 gives the FTIR spectrum of asphalt emulsifier (A) in Scheme 1. The absorption at 3250-3500 $\mathrm{cm}^{-1}$ (peak 1) is assigned to the superimposed peak of O-H and N-H stretching. The absorption at $2918 \mathrm{~cm}^{-1}$ (peak 2) is assigned to the methyl asymmetrical stretching. The absorption at $2846 \mathrm{~cm}^{-1}$ (peak 3) is assigned to the methylene symmetrical stretching. The absorption at $1737 \mathrm{~cm}^{-1}$ (peak 4) is assigned to $\mathrm{C}=\mathrm{O}$ stretching of carboxylic acid. The absorption at $1634 \mathrm{~cm}^{-1}$ (peak 5) is assigned to $\mathrm{C}=\mathrm{O}$ stretching of carboxylate. The absorptions at $1470 \mathrm{~cm}^{-1}$ (peak 6) and $1395 \mathrm{~cm}^{-1}$ (peak 7) are assigned to the methyl asymmetrical and symmetrical bending vibration, respectively. The absorption at 1207 $\mathrm{cm}^{-1}$ (peak 8) is assigned to C-N stretching. The absorption at $1068 \mathrm{~cm}^{-1}$ (peak 9) is assigned to $\mathrm{C}-\mathrm{OH}$ stretching. The absorption at $926 \mathrm{~cm}^{-1}$ (peak 10) is assigned to $\mathrm{O}-\mathrm{H}$ out-of-plane swing vibration of carboxylic acid. The absorption at $717 \mathrm{~cm}^{-1}$ (peak 11) is assigned to methylene in-plane swing vibration. Therefore, the FTIR spectrum agrees with the chemical structure of asphalt emulsifier (A) to be synthesized.

${ }^{1} \mathrm{H}$ NMR $\left(300 \mathrm{MHz}, \mathrm{D}_{2} \mathrm{O}\right), \delta: 0.81\left(\mathrm{t}, 3 \mathrm{H},-\mathrm{CH}_{3}\right), 1.22(\mathrm{~s}$, $\left.30 \mathrm{H},-\mathrm{CH}_{2}-\right), 1.66\left(\mathrm{~s}, 2 \mathrm{H}, \mathrm{CH}_{3}\left(\mathrm{CH}_{2}\right){ }_{15} \mathrm{CH}_{2}-\right), 2.16(\mathrm{~s}, 2 \mathrm{H},-$ $\mathrm{NH}^{+} \mathrm{CH}_{2} \mathrm{CH}_{2} \mathrm{CH}_{2} \mathrm{NH}^{+}$-), 2.59 (m, $2 \mathrm{H},-\mathrm{NH}^{+} \mathrm{CH}_{2} \mathrm{CH}_{2} \mathrm{COOH}$ ), 3.12-3.67(m, $8 \mathrm{H}$,

$\mathrm{CH}_{2} \mathrm{NH}^{+} \mathrm{CH}_{2} \mathrm{CH}_{2} \mathrm{CH}_{2} \mathrm{NH}^{+} \mathrm{CH}_{2} \mathrm{CH}_{2} \mathrm{COOH}$ ), 3.73-4.24(m, $4 \mathrm{H},-\mathrm{CH}_{2} \mathrm{COONa}$ ) ppm.

Anal.: Calcd. for $\mathrm{C}_{28} \mathrm{H}_{54} \mathrm{~N}_{2} \mathrm{O}_{6} \mathrm{Cl}_{2} \mathrm{Na}_{2}: \mathrm{C}, 46.47 \%$; $\mathrm{H}$, $6.92 \%$; N, $3.87 \%$. Found: C, $47.02 \%$; H, $9.43 \%$; N, $3.98 \%$.

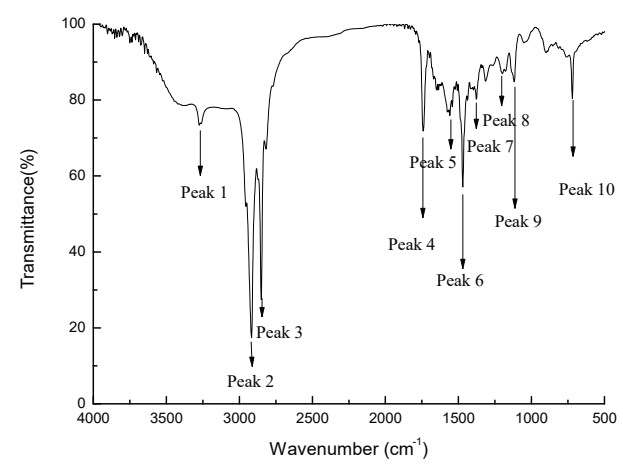

Figure 1. FTIR of intermediate in Scheme 1.

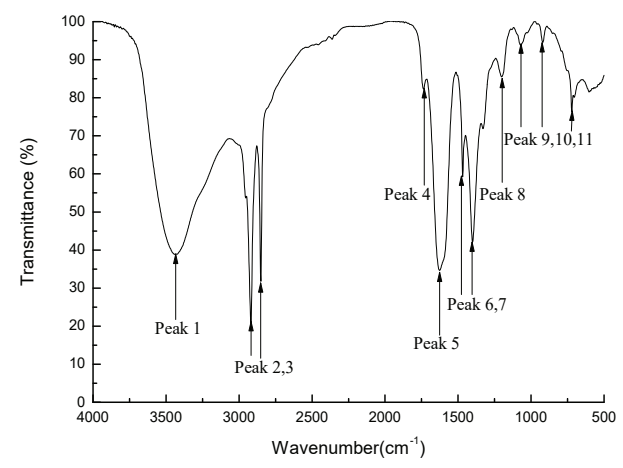

Figure 2. FTIR spectrum of asphalt emulsifier (A).

\subsection{Structure characterization of asphalt emulsifier (B)}

Figure 3 gives the FTIR spectrum of asphalt emulsifier (B) in Scheme 2. The absorption at 3250-3500 $\mathrm{cm}^{-1}$ (peak 1) is assigned to the superimposed peak of $\mathrm{O}-\mathrm{H}$ and $\mathrm{N}-\mathrm{H}$ stretching. The absorption at $2925 \mathrm{~cm}^{-1}$ (peak 2) is assigned to the methyl asymmetrical stretching. The absorption at $2850 \mathrm{~cm}^{-1}$ (peak 3) is assigned to the methylene symmetrical stretching. The absorption at $1735 \mathrm{~cm}^{-1}$ (peak 4) is assigned to $\mathrm{C}=\mathrm{O}$ stretching of carboxylic acid. The absorption at $1605 \mathrm{~cm}^{-1}$ (peak 5) is assigned to $\mathrm{C}=\mathrm{O}$ stretching of carboxylate. The absorptions at $1470 \mathrm{~cm}^{-1}$ (peak 6) and $1395 \mathrm{~cm}^{-1}$ (peak 7) are assigned to the methyl asymmetrical and symmetrical bending vibration, respectively. The absorption at 1254 $\mathrm{cm}^{-1}$ (peak 8) is assigned to C-N stretching. The absorption at $1068 \mathrm{~cm}^{-1}$ (peak 9) is assigned to $\mathrm{C}-\mathrm{OH}$ stretching. The absorption at $917 \mathrm{~cm}^{-1}$ (peak 10) is assigned to $\mathrm{O}-\mathrm{H}$ out-of-plane swing vibration of carboxylic acid. The absorption at $701 \mathrm{~cm}^{-1}$ (peak 11) is assigned to methylene in-plane swing vibration. Therefore, the FTIR spectrum agrees with the chemical structure of asphalt emulsifier (B) to be synthesized.

${ }^{1} \mathrm{H}$ NMR $\left(300 \mathrm{MHz}, \mathrm{D}_{2} \mathrm{O}\right), \delta: 0.85\left(\mathrm{t}, 3 \mathrm{H},-\mathrm{CH}_{3}\right), 1.26(\mathrm{~s}$, $\left.30 \mathrm{H},-\mathrm{CH}_{2}-\right), 1.70\left(\mathrm{~s}, 2 \mathrm{H}, \mathrm{CH}_{3}\left(\mathrm{CH}_{2}\right){ }_{15} \mathrm{C}_{2}-\right), 2.24(\mathrm{~s}, 2 \mathrm{H}$, $\left.\mathrm{NH}^{+} \mathrm{CH}_{2} \mathrm{CH}_{2} \mathrm{CH}_{2} \mathrm{~N}^{+}-\right), 2.57-2.64\left(\mathrm{~m}, 4 \mathrm{H},-\mathrm{CH}_{2} \mathrm{C}_{2} \mathrm{COOH}\right)$, 3.01-3.58(m, $\quad 10 \mathrm{H}$,

$\left.\mathrm{CH}_{2} \mathrm{NH}^{+} \mathrm{CH}_{2} \mathrm{CH}_{2} \mathrm{CH}_{2} \mathrm{~N}^{+}\left(\mathrm{CH}_{2} \mathrm{CH}_{2} \mathrm{COOH}\right)_{2}\right)$,

$3.83-$ $4.28\left(\mathrm{~s}, 4 \mathrm{H},-\mathrm{CH}_{2} \mathrm{COONa}\right) \mathrm{ppm}$.

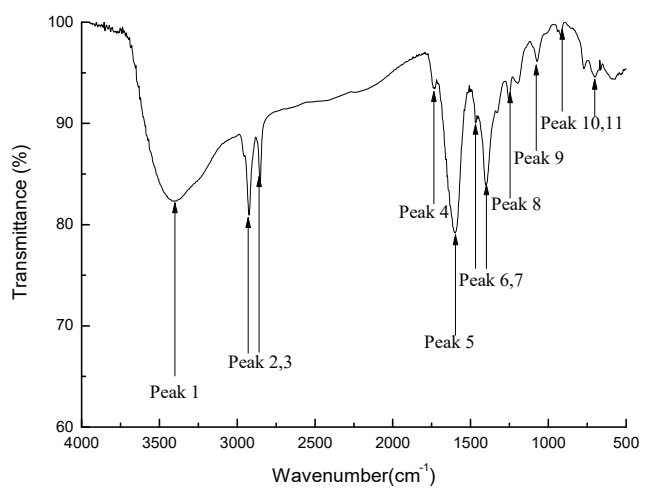

Figure 3. FTIR spectrum of asphalt emulsifier (B).

\subsection{Structure characterization of asphalt emulsifier (C)}

Figure 4 gives the FTIR spectrum of asphalt emulsifier (C) in Scheme 3. The absorption at $3427 \mathrm{~cm}^{-1}$ (peak 1) is assigned to O-H stretching. The absorption at $2925 \mathrm{~cm}^{-1}$ (peak 2) is assigned to the methyl asymmetrical stretching. The absorption at $2854 \mathrm{~cm}^{-1}$ (peak 3) is assigned to the methylene symmetrical stretching. The absorption at $1733 \mathrm{~cm}^{-1}$ (peak 4) is assigned to $\mathrm{C}=\mathrm{O}$ stretching of carboxylic acid. The absorption at $1606 \mathrm{~cm}^{-1}$ (peak 5) is assigned to $\mathrm{C}=\mathrm{O}$ stretching of carboxylate. The absorptions at $1463 \mathrm{~cm}^{-1}$ (peak 6) and $1395 \mathrm{~cm}^{-1}$ (peak 7) are assigned to the methyl asymmetrical and symmetrical bending vibration, respectively. The absorptions at $1261 \mathrm{~cm}^{-1}$ (peak 8) and $1197 \mathrm{~cm}^{-1}$ (peak 9) 
are assigned to $\mathrm{C}-\mathrm{N}$ stretching. The absorption at 1072 $\mathrm{cm}^{-1}$ (peak 10) is assigned to $\mathrm{C}-\mathrm{OH}$ stretching. The absorption at $930 \mathrm{~cm}^{-1}$ (peak 11) is assigned to $\mathrm{O}-\mathrm{H}$ outof-plane swing vibration of carboxylic acid. The absorption at $772 \mathrm{~cm}^{-1}$ (peak 12) is assigned to methylene in-plane swing vibration. Therefore, the FTIR spectrum agrees with the chemical structure of asphalt emulsifier (C) to be synthesized.

${ }^{1} \mathrm{H}$ NMR $\left(300 \mathrm{MHz}, \mathrm{D}_{2} \mathrm{O}\right), \delta: 0.85\left(\mathrm{t}, 3 \mathrm{H},-\mathrm{CH}_{3}\right), 1.25(\mathrm{~s}$, $\left.30 \mathrm{H},-\mathrm{CH}_{2}-\right), 1.70\left(\mathrm{~s}, 2 \mathrm{H}, \mathrm{CH}_{3}\left(\mathrm{CH}_{2}\right){ }_{15} \mathrm{CH}_{2}-\right), 2.24(\mathrm{~s}, 2 \mathrm{H}$, $\left.\mathrm{N}^{+} \mathrm{CH}_{2} \mathrm{CH}_{2} \mathrm{CH}_{2} \mathrm{~N}^{+}-\right), \quad 2.63-2.85\left(\mathrm{~m}, 6 \mathrm{H},-\mathrm{CH}_{2} \underline{\mathrm{CH}}_{2} \mathrm{COOH}\right)$, 2.93-3.51(m, $12 \mathrm{H}, \quad-\mathrm{CH}_{2} \mathrm{~N}^{+}\left(\mathrm{CH}_{2} \mathrm{CH}_{2} \mathrm{COOH}\right)-$ $\left.\mathrm{C}_{2} \mathrm{CH}_{2} \underline{\mathrm{C}}_{2} \mathrm{~N}^{+}\left(\mathrm{C}_{2} \mathrm{CH}_{2} \mathrm{COOH}\right)_{2}\right), \quad 3.89-4.25(\mathrm{~s}, 4 \mathrm{H}$, $\mathrm{C}_{2} \mathrm{COONa}$ ) ppm.

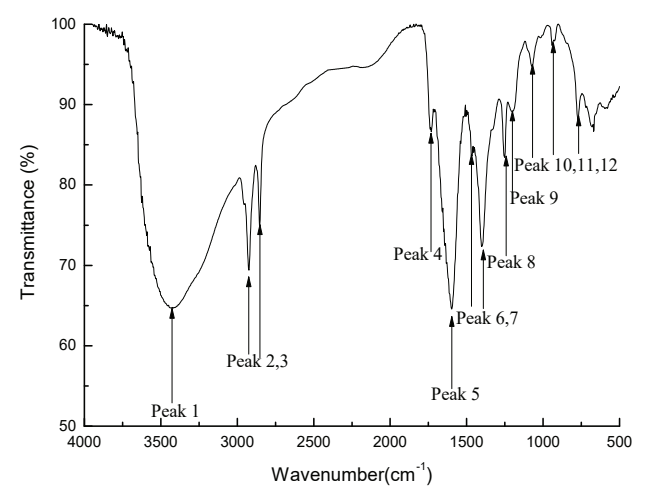

Figure 4. FTIR spectrum of asphalt emulsifier (C).

\subsection{Demulsification speed test of bituminous emulsion}

The emulsifiers have excellent emulsifying ability to AH90 asphalt. The prepared bituminous emulsion showed higher storage stability. Table 1 gives the mixing time and the types of the asphalt emulsifiers. It can be designed to perform in a wide variety of applications including tack coat, fog seal, chip seal and slurry seal in asphalt pavement construction.

Table 1. Demulsification speed test of bituminous emulsion.

\begin{tabular}{|c|c|c|}
\hline $\begin{array}{c}\text { asphalt } \\
\text { emulsifier }\end{array}$ & $\begin{array}{c}\text { mixing time } \\
(\mathrm{s})\end{array}$ & $\begin{array}{c}\text { types of the asphalt } \\
\text { emulsifier }\end{array}$ \\
\hline A & 12 & medium-set \\
\hline B & 47 & slow-set \\
\hline C & 14 & medium-set \\
\hline
\end{tabular}

\section{Summary}

Three novel bis-cationic asphalt emulsifiers were synthesized by two steps reaction of N-tallow-1,3diaminopropane, methyl acrylate, sodium hydroxide and chloroacetic acid. The emulsifier belongs to medium-set and slow-set asphalt emulsifier. It can be designed to perform in a wide variety of applications including tack coat, fog seal, chip seal and slurry seal in asphalt pavement construction.

\section{Acknowledgement}

The authors would like to thank the financial support from the Shandong Provincial Science and Technology Project (No. 2015GGX107005).

\section{References}

1. F. Yang, G. Li, J. Qi, et al. Synthesis and surface activity properties of alkylphenol polyoxyethylene nonionic trimeric surfactants. Applied Surface Science, 257, 312-318(2010)

2. K. Isobe, R. Tamaki. Nonionic emulsifier for asphalt. U.S. Patent 6,114,418. (2000)

3. P.R.J. Blanpain, J.W. Creak, G.F. Mori, et al. Cationic asphalt emulsions. U.S. Patent 4,997,868. (1991)

4. N.A. Negm, M.A. El-Hashash, D.E. Mohamed, et al. Gemini cationic surfactants: synthesis and influence of chemical structure on the surface activity. Journal of Surfactants and Detergents, 16, 733-738(2013)

5. H.P. Li, H. Zhao, K. Liao. The preparation of asphalt emulsions with dissymmetric Gemini quaternary ammonium salts cationic surfactants. Energy Sources, Part A: Recovery, Utilization, and Environmental Effects, 35, 2285-2293(2013)

6. W.A. Mclntosh. Alkali lignin to stabilize slow-break asphalt emulsions. Industrial \& Engineering Chemistry, 44, 1656-1659(1952)

7. X. Zhi, W. Wang, Y. Tsai. Cost-benefit timing for applying slurry seal on actual roadway tests in China. Journal of Central South University, 19, 23942402(2012)

8. P. Goullet, P. Scotte. Method of making fastbreaking bituminous emulsions. U.S. Patent 4,338,136. (1982)

9. A.C. Ludwig. Emulsification of rock asphalt. U.S. Patent 5,089,052. (1992)

10. C. Huai, L. Shi, N. Li. Synthesis of a novel betainetype asphalt emulsifier and its investigation by online FTIR spectrophotometry. Research on Chemical Intermediates, 39, 597-614(2013)

11. L. Shi, M. Sun, N. Li, B. Zhang. A novel betaine type asphalt emulsifier synthesized and investigated by online FTIR spectrophotometric method. Chem. Ind. Chem. Eng. Q., 21, 113-121(2015)

12. L. Shi, Y. Zhao. Synthesis and performance evaluation of a Gemini cationic asphalt emulsifier. Petroleum asphalt, 24(6), 66-71(2010)

13. N. Li, L. Shi, X. Gong, Q. Xu, X. Liu, X. Wang. Synthesis of a novel cationic asphalt emulsifier and its investigation by online FTIR spectrophotometry. Res. Chem. Intermed., 41(4), 1935-1950(2015)

14. X. Tao, L. Shi, M. Sun, N. Li. Synthesis of lignin amine asphalt emulsifier and its investigation by 
online FTIR spectrophotometry. Advanced Materials Research, 909, 72-76(2014) 